\title{
Assessment of surgical treatment of Eagle's syndrome
}

Authors' Contribution: A-Study Design

B-Data Collection

C-Statistical Analysis

D-Data Interpretation

-Manuscript Preparation

F-Literature Search

G-Funds Collection

Article history: Received: 15.01.2019 Accepted: 22.03.2019 Published: 05.04.2019

\author{
Marcin Czajka ${ }^{A C D E F}$, Mariusz Szuta ${ }^{A E}$, Jan Zapała ${ }^{A E}$, Iga Janecka ${ }^{A B D E F}$ \\ Department of Craniomaxillofacial, Oncological and Reconstruction Surgery, Institute of Dentistry, Jagiellonian University Medical College \\ in Kraków, Poland; Department Head: Prof. Jan Zapała MD, PhD
}

ABSTRACT:

Introduction: The aim of the study was to assess the effectiveness of surgical treatment of patients with Eagle's syndrome, taking into account both early and late results.

Material and methods: The study group consisted of 15 patients who underwent resection of the styloid process due to Eagle syndrome in the period of 2005-2017. During the follow-up visit, the patients were asked to fill in a post-operative questionnaire that compared the pre-operative symptoms and their severity with the patients' current health condition. The VAS pain scale was used to assess each symptom, and the Laitinen scale was used to assess the quality of life. Data from patients' medical records were also included. The results of the surveys were subjected to statistical analysis.

Results: The study showed that in 11 out of 15 cases there was a significant improvement in the level of pain (70.5\% on average) and an improvement in quality of life (on average 65\%) comparing to the pre-operative condition. The Wilcoxon test for binding pairs, the Mann-Whitney test, the Kruskal-Wallis test and the Spearman correlation coefficient were used in the statistical analysis. There were statistically significant correlations between the recorded improvement rate and the length of the resected styloid process and its setting.

Discussion: The study proved that resection of prolonged styloid process from extraoral approach in most cases is an effective method of treatment of Eagle syndrome, that carries low risk of complications.

KEYWORDS: $\quad$ Eagle's syndrome, odynophagia, stylocarotid syndrome, styloid process

\section{INTRODUCTION}

Elongated styloid process syndrome, first described by American otolaryngologist Watt Weems Eagle in 1937, is a rare facial pain syndrome affecting ca. $0.4 \%$ of population. It is characterized by elongation of the styloid process of the temporal bone (above $3 \mathrm{~cm}$ in length) and, in some cases, calcification of stylohyoid ligament. Hyperplasia of these anatomical structures may develop as the result of trauma, genetic conditions, surgical procedures, or hormonal disorders $[3,7,8,13]$.

Two main types of Eagle's syndrome were identified, namely the classic Eagle's syndrome and stylocarotid syndrome. The former involves cranial nerves being impinged within the parapharyngeal space between the excessively long styloid process and a connective tissue scar formed following the resection of palatine tonsil. It is characterized by throat pain, frequently radiating towards the ear and exacerbating upon mastication, swallowing, and head movements, globus sensation, odynophagia, dysphagia, and, in some cases, lockjaw and restricted lateral mandible movements. The stylocarotid syndrome develops when the elongated styloid process mechanically irritates the sympathetic nerve fibers which coil the carotid arteries. The impingement of the external carotid artery may cause pain within the infraorbital, temporal, parietal, and auricular regions. The impingement of internal carotid artery leads to unilateral headache, frequently misdiagnosed as migraine pain. Syncopes may also be observed $[2,7,8,9]$.

Diagnosis is based on precise clinical examination including data on the duration, location, and nature of pain. In most cases, the disease may last for years, and patients are treated, with poor outcomes, by physicians of many specialties, including neurologists, otolaryngologists, psychiatrists, gastroenterologists, and dentists. Palpation of the palatine tonsil bed may reveal the hard, sharp apex of the enlarged styloid process. The diagnosis of Eagle's syndrome may be confirmed by transient resolution of pain following $1 \mathrm{~mL}$ of $1 \%$ lignocaine being administered into the palatine tonsil bed region $[4,5,7,13]$.

The correctness of clinical diagnosis is confirmed by classic computed tomography scans performed to determine both the length of the styloid process and its position relative to carotid arteries and parapharyngeal space cranial nerves. According to most authors, CT scans with $3 \mathrm{D}$ reconstruction are the most useful tool for visualization of the elongated styloid process and stylohyoid ligament (Fig. 1.) [5, 13].

Due to the low prevalence of the Eagle's syndrome, differential diagnostics should include head and neck inflammations (temporal arteritis, chronic tonsillitis, otitis media or externa, styloiditis, 
submandibular sialadenitis, pulpitis), cranial nerve disorders (trigeminal neuralgia, pterygopalatine ganglion neuralgia, glossopharyngeal neuralgia), temporomandibular joint disorders, presence of foreign bodies, and benign or malignant tumors within the naso - and oropharynx $[7,13]$.

Conservative treatment may be pursued in classic-type Eagle's syndrome developing following a tonsillectomy procedure. The treatment consists in infiltration of the palatine tonsil bed using local anesthetics and steroids. Oral anticonvulsants, e.g. carbamazepine, are also administered. This management, however, is usually inefficient $[7,9,13]$.

Modern surgical treatment of the Eagle's syndrome consists in the shortening of the elongated styloid process, with the surgical access remaining a matter of dispute. Intraoral access consists of the first stage involving the resection of the palatine tonsil (if no tonsillectomy had been performed before) followed by the second stage involving the incision of the tonsillar bed mucosa and partial resection of the process. Benefits of this technique consist in the possibilities to avoid a skin scar and to perform the procedure under local anesthesia. However, the technique is associated with a high risk of complications due to the poor visibility of the operating field resulting in a likelihood of important anatomical structures within the parapharyngeal space being damaged in the course of the procedure. Another complication may consist in the infection of the parapharyngeal space and the neck. Isolated cases of facial nerve damage were also reported. In some cases, endoscopic guidance is used to perform the procedures from the intraoral access to increase their safety $[1,2,4,6,7,9,10,11,13,14]$.

Extraoral access is recommended as being safer due to good intraoperative visibility and lower risk of inflammatory complications. However, extraoral-access styloidectomy has to be performed under general anesthesia and leaves a neck skin scar. Neuronavigation should be employed during the procedure to reduce the risk of intraoperative damage to the marginal mandibular branch of the facial nerve $[2,4,6,7,9,10,13]$.

The estimated efficacy of the surgical management of Eagle's syndrome is about $80 \%$. Treatment failures may be due to the incompletely understood etiology of the disorder, difficulties in determining the actual cause of symptoms, and fixation of nociception pathways within the CNS $[6,7,9,12,13]$.

The objective of this study was to assess the efficacy of surgical management of Eagle's syndrome and to assess the improvement in the quality of life in patients having undergone elongated styloid process resection surgeries.

\section{MATERIAL AND METHODS}

The study group consisted of 6 male and 9 female patients at the mean age of 51 years, who had undergone resection of elongated styloid process at the Department of Craniomaxillofacial, Oncological and Reconstruction Surgery, Institute of Dentistry, Jagiellonian University Medical College in Kraków, between 2005

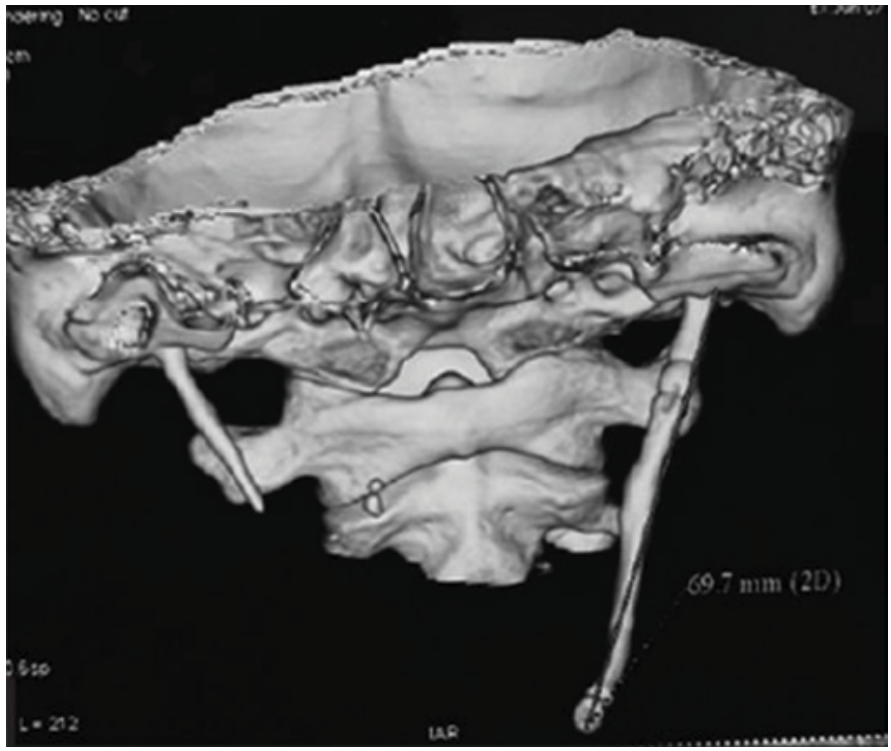

Fig. 1. Right styloid process elongation in CT scans with 3D reconstruction.

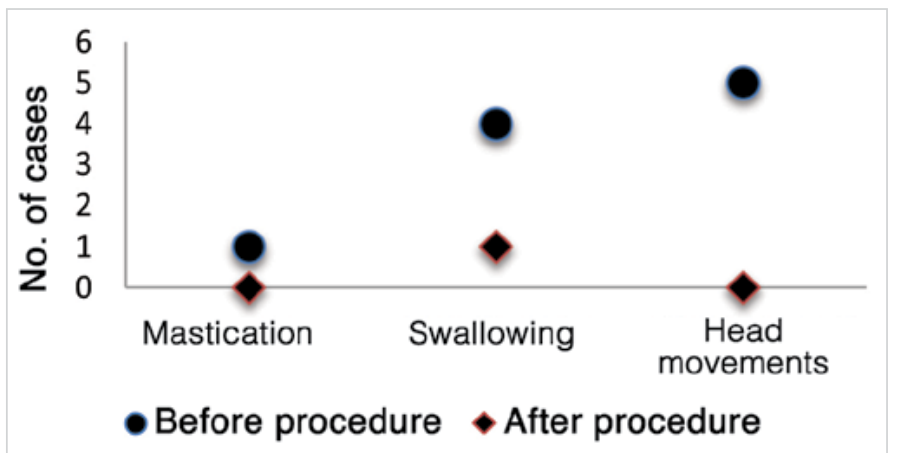

Fig. 2. Comparison of pre-and postprocedural intensification of pain upon mastication, swallowing, and head movements.

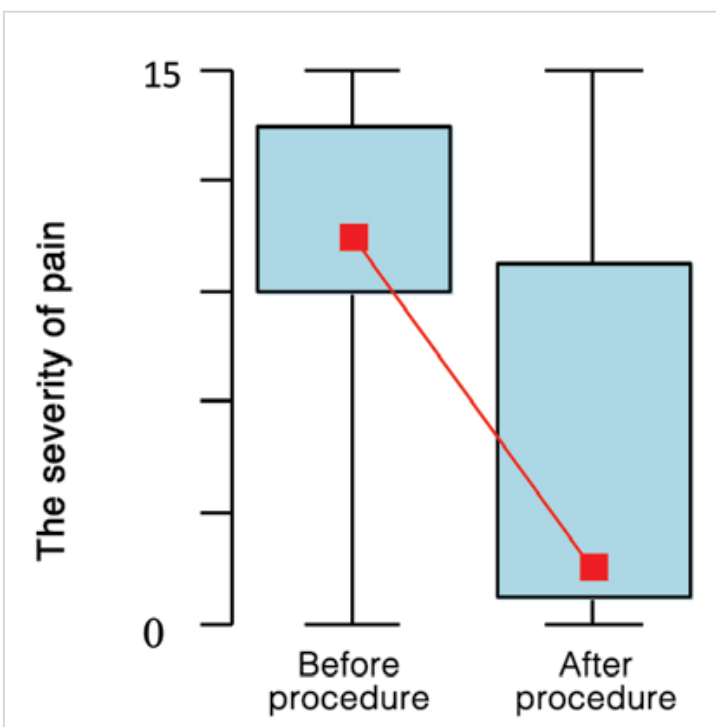

Median Quartiles I Range

Fig. 3. Intensity of pain before and after surgical management of Eagle's syndrome. 
Tab. I. Summary of clinical cases included in the study.

\begin{tabular}{|c|c|c|c|c|c|c|c|}
\hline CASE & SEX & AGE & OPERATED SIDE & SYMPTOMS & DISEASE DURATION & HISTORY OF TONSILLECTOMY & ACCESS \\
\hline 1. & $\mathrm{~K}$ & 61 & $P$ & $\mathrm{JP}$ & Several years & $\mathrm{N}$ & Z \\
\hline 2. & $M$ & 53 & $\mathrm{~L}$ & J & 3 years & $\mathrm{N}$ & Z \\
\hline 3. & $\mathrm{~K}$ & 47 & $\mathrm{~L}$ & 了 & 6 years & $\mathrm{T}$ & Z \\
\hline 4. & $\mathrm{~K}$ & 49 & $\mathrm{P}$ & $\mathrm{JP}$ & 9 years & $\mathrm{T}$ & Z \\
\hline 5. & $\mathrm{~K}$ & 51 & $\mathrm{~L}$ & J & 1 year & $\mathrm{T}$ & Z \\
\hline 6. & $\mathrm{~K}$ & 66 & $\mathrm{~L}$ & J & 2 years & $\mathrm{T}$ & Z \\
\hline 7. & $\mathrm{~K}$ & 37 & $\mathrm{~L}$ & ] & 2.5 months & $\mathrm{N}$ & Z \\
\hline 8. & M & 68 & $\mathrm{~L}$ & \multicolumn{2}{|c|}{ Tonsillectomy w/ resection } & $\mathrm{N}$ & W \\
\hline 9. & $\mathrm{~K}$ & 49 & $\mathrm{~L}$ & ] & 2 years & $\mathrm{N}$ & Z \\
\hline 10. & $\mathrm{~K}$ & 35 & $\mathrm{~L}$ & $\mathrm{O}$ & 10 months & $\mathrm{N}$ & Z \\
\hline 11. & $M$ & 41 & $\mathrm{~L}$ & $\mathrm{O}$ & 8 years & $\mathrm{N}$ & Z \\
\hline 12. & $\mathrm{~K}$ & 60 & $\mathrm{P}$ & J & 2 years & $\mathrm{N}$ & Z \\
\hline 13. & $M$ & 45 & $\mathrm{P}$ & J & 3 years & $\mathrm{N}$ & Z \\
\hline 14. & $M$ & 56 & $\mathrm{P}$ & 0 & 5 years & $\mathrm{N}$ & Z \\
\hline 15. & $M$ & 47 & $\mathrm{~L}$ & J & 2 years & $\mathrm{T}$ & Z \\
\hline
\end{tabular}

Legend: L-left, $\mathrm{R}$-right, $\mathrm{U}$-unilateral, $\mathrm{B}$ - bilateral, $\mathrm{UC}$ - unilateral with subsequent contralateral, $\mathrm{E}$-extraoral, I-intraoral, $\mathrm{N}$-no, $\mathrm{Y}$-yes.

Tab. II. Resolution of pain symptoms.

\begin{tabular}{|c|c|c|c|c|c|c|}
\hline \multirow{2}{*}{ CASE } & \multicolumn{2}{|c|}{ MEAN INTENSITY OF PAIN (VAS SCALE) } & \multicolumn{2}{|c|}{ QUALITY OF LIFE (LAITINEN SCALE) } & \multirow{2}{*}{ PAIN RESOLUTION } & \multirow{2}{*}{$\begin{array}{l}\text { QUALITY OF LIFE } \\
\text { IMPROVEMENT }\end{array}$} \\
\hline & BEFORE PROCEDURE & AFTER PROCEDURE & BEFORE PROCEDURE & AFTER PROCEDURE & & \\
\hline 1. & 5.8 & 2 & 4 & 2 & $66 \%$ & $50 \%$ \\
\hline 2. & 4.75 & 2.75 & 5 & 3 & $42 \%$ & $40 \%$ \\
\hline 3. & 8.8 & 0.6 & 8 & 1 & $93 \%$ & $87.5 \%$ \\
\hline 4. & 6.0 & 0.0 & 7 & 2 & $100 \%$ & $71.4 \%$ \\
\hline 5. & 6.0 & 1.0 & 7 & 2 & $83.3 \%$ & $71.4 \%$ \\
\hline 6. & 5.0 & 3.7 & 6 & 6 & $26 \%$ & ०\% \\
\hline 7. & 9.0 & 0.0 & 9 & 0 & $100 \%$ & $100 \%$ \\
\hline 8. & 8 & 3.5 & 8 & 1 & 56.2 & $50 \%$ \\
\hline 9. & 7.0 & 0.3 & 6 & 1 & $96 \%$ & $83.3 \%$ \\
\hline 10. & 7.6 & 7.3 & 7 & 6 & $4 \%$ & $14.2 \%$ \\
\hline 11. & 8.75 & 7.75 & 6 & 4 & $11.4 \%$ & $33.3 \%$ \\
\hline 12. & 8.8 & 0.5 & 8 & 1 & $94.3 \%$ & $94 \%$ \\
\hline 13. & 9.4 & 1 & 9 & 1 & $89.3 \%$ & $89 \%$ \\
\hline 14. & 7.3 & 0 & 8 & 0 & $100 \%$ & $100 \%$ \\
\hline 15. & 8.5 & 0.3 & 8 & 1 & $96.4 \%$ & $87.5 \%$ \\
\hline Average & & & & & $70.52 \%$ & $65 \%$ \\
\hline
\end{tabular}

and 2017. Extraoral access had been used in 14 patients whereas 1 patient had undergone an intraoral access surgery (Tab. I.).

Patients were asked to fill in a post-operative questionnaire to compare the presence and severity of preoperative symptoms and quality of life with their current health condition. The VAS pain scale was used to assess each symptom, and the Laitinen scale was used to assess the quality of life both before and after the procedure (Tab. II.). The time points of the follow-up visits ranged between 3 months and 6 years after the procedure, with the average follow-up time point of 25 months. Medical documentation of study patients was assessed using the Project $\mathrm{R}$ software version 3.3.0. Pain intensity was compared using the Wilcoxon matched pair test, Mann-Whitney test, and Kruskal-Wallis; distribution normality was evaluated using using the Shapiro-Wilk test. The significance level was defined as $\mathrm{P} \leq 0.05$.

\section{RESULTS}

As shown by the study results, the most common symptoms included otalgia, odynophagia, globus sensation, retromandibular 
Tab. III. Most common symptoms of Eagle's syndrome as observed in the study group.

\begin{tabular}{|lll|}
\hline SYMPTOM & NO. OF CASES & FREQUENCY \\
\hline Otalgia & 10 & $62.5 \%$ \\
\hline Dysphagia/odynophagia & 9 & $56.2 \%$ \\
\hline Clobus sensation & 8 & $50 \%$ \\
\hline $\begin{array}{l}\text { Unilateral pain of face and neck } \\
\text { Burning within the posterior }\end{array}$ & 6 & $37.5 \%$ \\
segment of tongue & 4 & $25 \%$ \\
\hline Dizziness & 2 & $12.5 \%$ \\
\hline
\end{tabular}

neck pain radiating to ipsilateral mandible or ear, burning within the posterior segment of the tongue, and periodical dizziness (Tab. III.).

The symptoms exacerbated upon mastication, swallowing, and head movements (Fig. 2.). Most patients first reported these symptoms to neurologists, dentists, otolaryngologists, and pain treatment clinics. In 2 cases, conservative treatment had been attempted using anticonvulsants and nonsteroidal anti-inflammatory drugs, albeit to no effect. Prior to the diagnosis of Eagle's syndrome, orthopantomography, magnetic resonance, and, most frequently, computed tomography scans had been performed in patients. History of tonsillectomy was recorded in 4 cases.

All patients had been admitted to the department with the diagnosis of Eagle's syndrome and were subjected to surgical treatment consisting in the resection of the elongated styloid process of the temporal bone. In 14 patients, the surgery was performed from extraoral access within a neck fold. Facial nerve stimulator was used upon tissue dissection to identify and preserve the marginal mandibular branch of the facial nerve. Only 1 was subjected to the surgery from an intraoral access location following previous tonsillectomy. The mean time of the procedures was $45 \mathrm{~min}$ utes. No intraoperative complications were observed. The mean length of styloid processes was $5.75 \mathrm{~cm}$ while the mean length of the resected segment was $3.05 \mathrm{~cm}$. Only one patient experienced marginal mandibular branch paresis to resolve after 3 months. In addition, no comments were made during the follow-up visits regarding the patients' neck scars.

The analysis of the results of postoperative survey carried out using a VAS pain intensity scale and a Laitinen quality of life scale assessments revealed a statistically significant reduction of symptoms following the resection of elongated styloid process $(P=0.048)$. Thus, the efficacy of surgical management of the Eagle's syndrome was demonstrated. Graphical representation of the results is presented in Fig. 3. while detailed analysis presented in Tab. IV.

A statistically significant correlation was also demonstrated between the length of the resected styloid process and the degree of pain resolution $(\mathrm{P}<0.048)$. Best outcomes of the surgical treatment were obtained in patients in whom the length of the styloid process was greater than $6 \mathrm{~cm}$ (Tab. V.).

Further statistical analysis revealed that resolution of pain depended, in addition to the length of the styloid process, on its position relative to the neighboring anatomical structures. Best results of surgical treatment were obtained in patients in whom the styloid process was intraoperatively found to be adjacent to the lateral pharyngeal wall and in direct contact with internal carotid artery and/or cranial nerves within the parapharyngeal space $(\mathrm{P}<0.045)$. Details are listed in Tab. VI.

No correlation was identified by means of statistical analysis between the length of the resected styloid process segment and the resolution of pain in the patients (Tab. VII.).

The correlation coefficient between the duration of the disease and postoperative change in the intensity of symptoms was found to equal 0.04 and was statistically insignificant $(\mathrm{P}>0.05)$; thus, both characteristics are not significantly dependent on each other (Tab. VIII.).

\section{DISCUSSION}

The styloid process of the temporal bone is a long, slender anatomical structure located within the skull base anteriorly and medially from the mastoid process. The styloid process is the point of attachment for the bundle of Riolan, i.e. the stylopharyngeus muscle, styloglossus muscle, and stylohyoid muscle as well as for the stylomandibular and stylohyoid ligaments. Numerous important anatomical neck structures are located in direct vicinity of the styloid process, including the internal carotid artery, external carotid artery and its ramification into the maxillary and superficial temporal arteries internal jugular vein, glossopharyngeal nerve, vagus nerve, spinal accessory nerve, hypoglossal nerve, as well as the branches of the trigeminal and facial nerves, carotid segment of the sympathetic trunk, or the branches of ansa cervicalis. The location and relative position of the styloid process and, in some cases, the calcified stylohyoid ligament as compared to these structures are crucial in the pathophysiology of the Eagle's syndrome $[11,13]$.

The length of the styloid process differs between individuals. Processes longer than $3 \mathrm{~cm}$ are considered to be elongated $[3,8]$. In the literature, the incidence of elongated styloid process is estimated at 3.3 to $4 \%$; however, symptoms of Eagle's syndrome are observed in as little as $4 \%$ of this population $[1,4,9,10,13,14]$. What's more, despite the elongation being bilateral, symptoms are usually experienced on one side only (86.2\%), as was also confirmed in our study group $[1,2,13]$. Epidemiological studies on the Eagle's syndrome reveal that it is more common in females and patients above the age of 30, which was also confirmed by our analysis (F:M ratio of 2.6:1, all patients above the age of 30) $[1,2,6,10,12,13]$.

The analysis of available literature shows that resolution or significant reduction of pain following surgical management of Eagle's syndrome is observed in about $80 \%$ of cases $[6,7,9,12,13]$. Reported causes of failures include incompletely understood etiology of the disease and the resulting difficulties in identification of actual causes of symptoms as well as other concomitant diseases which cannot ruled out in the subjective patient's assessment [7]. As shown by our analysis, significant reduction or resolution of disease symptoms following the resection of elongated styloid process was observed in $70.5 \%$ of cases whereas improvement in the quality of life was 
Tab. IV. Intensity of pain before and after surgery.

\begin{tabular}{|c|c|c|c|c|c|c|c|c|c|}
\hline \multirow{2}{*}{ MEASUREMENT } & \multicolumn{9}{|c|}{ PAIN INTENSITY } \\
\hline & $\mathrm{N}$ & AVERAGE & SD & MEDIAN & MIN & MAX & $1^{\text {ST }}$ QUARTILE & $3^{\text {RD }}$ QUARTILE & $P^{*}$ \\
\hline Before procedure & 15 & 6.82 & 2.86 & 7 & 0 & 10 & 6 & 9 & \\
\hline After procedure & 15 & 3.73 & 4 & 1 & 0 & 10 & 0.5 & 6.5 & \\
\hline
\end{tabular}

*Wilcoxon matched-pair test.

Tab. V. Resolution of pain vs. the length of resected styloid process.

\begin{tabular}{|c|c|c|c|c|c|c|c|c|c|}
\hline \multirow{2}{*}{ PROCESS LENGTH } & \multicolumn{9}{|c|}{ CHANGE IN PAIN INTENSITY } \\
\hline & $\mathbf{N}$ & AVERAGE & SD & MEDIAN & MIN & MAX & Q1 & Q3 & $\mathbf{P}^{*}$ \\
\hline Up to $6 \mathrm{~cm}$ & 5 & 1.67 & 2.89 & 0 & 0 & 5 & 0 & 2.5 & \\
\hline $6 \mathrm{~cm}$ & 4 & 3.5 & 4.12 & 3 & 0 & 8 & 0 & 6.5 & $p=0.048$ \\
\hline More than $6 \mathrm{~cm}$ & 6 & 3.73 & 4.5 & 3 & 0 & 9 & 0 & 6.75 & \\
\hline
\end{tabular}

*Kruskal-Wallis test

Tab. VI. Resolution of pain vs. the position of resected styloid process.

\begin{tabular}{|c|c|c|c|c|c|c|c|c|c|}
\hline \multirow{2}{*}{ PROCESS POSITION } & \multicolumn{9}{|c|}{ CHANCE IN PAIN INTENSITY } \\
\hline & $\mathbf{N}$ & AVERAGE & SD & MEDIAN & MIN & MAX & Q1 & Q3 & $\mathbf{p}^{x}$ \\
\hline *Abnormal & 9 & 2.6 & 3.71 & 0 & 0 & 8 & 0 & 5 & \\
\hline$\because$ Normal & 6 & 3.5 & 3.99 & 3 & 0 & 9 & 0 & 6 & t5 \\
\hline
\end{tabular}

xest Mann-Whitney test.

Process position: 1. towards the lateral pharyngeal wall, 2. in direct vicinity of internal carotid artery, 3. in direct vicinity of parapharyngeal space nerves.

*** Elongated styloid process not in contact with large carotid vessels of cranial nerves.

reported by $65 \%$ of patients. On the basis of the statistical analysis of the intensity of pain experienced before and after styloidectomy, the procedure was shown to be an efficient method for the management of Eagle's syndrome ( $\mathrm{P}=0.048$ ) which, when performed from extraoral access with neuronavigation support, was also associated with a low rate of postoperative complications (6.7\%).

Patients with the lowest improvement scores presented with concomitant pathologies such as degenerative disc disease within the carotid spine, which possibly affected the subjective self-assessment of the quality of life and pain intensity.

The statistical analysis performed as part of this study demonstrated that the length of the elongated styloid process was associated with the resolution of pain. Best outcomes were reported by patients in whom preoperative process length was $6 \mathrm{~cm}$ or more $(\mathrm{P}<0.048)$.

Statistically significant correlation was also identified in the study between resolution of pain and the position of the styloid process. Best results of surgical treatment were obtained in patients in whom the styloid process was intraoperatively found to be in direct contact with internal carotid artery and/or cranial nerves within the parapharyngeal space or adjacent to the lateral pharyngeal wall $(\mathrm{P}<0.045)$. To date, no analyses of correlations of this type were available in the literature. The relationship suggests that when diagnosing patients with the suspicion of Eagle's syndrome, CT scans should be performed to assess both the length of the elongated styloid process and its location and position relative to anatomical structures listed above.

No significant correlation was identified in the statistical analysis between the treatment outcomes and the length of the resected segment of the styloid process $(\mathrm{P}=0.745)$.
Tab. VII. Resolution of pain vs. the position of resected styloid process.

$\begin{array}{lllll}\text { CHARACTERISTICS } & \begin{array}{l}\text { CORRELATION } \\ \text { COEFFICIENT* }\end{array} & \text { P } & \begin{array}{l}\text { CORRELATION } \\ \text { DIRECTION }\end{array} & \begin{array}{l}\text { CORRELATION } \\ \text { STRENGTH }\end{array} \\ \begin{array}{l}\text { Length of resected } \\ \text { styloid process vs. } \\ \text { change in pain intensity }\end{array} & -0.111 & 0.745 & - & - \\ \text { " Spearman's correlation coefficient. } & & & \\ \end{array}$

Tab. VIII. Resolution of pain vs. the duration of symptoms.

\begin{tabular}{lllll|}
\hline CHARACTERISTICS & $\begin{array}{l}\text { CORRELATION } \\
\text { COEFFICIENT* }\end{array}$ & $P$ & $\begin{array}{l}\text { CORRELATION } \\
\text { DIRECTION }\end{array}$ & $\begin{array}{l}\text { CORRELATION } \\
\text { STRENGTH }\end{array}$ \\
$\begin{array}{l}\text { Duration of symptoms } \\
\begin{array}{l}\text { vs. change in pain } \\
\text { intensity }\end{array}\end{array}$ & -0.04 & 0.914 & - & - \\
\hline
\end{tabular}

*Spearman's correlation coefficient.

In addition, the correlation coefficient between the duration of the disease before the surgery and postoperative change in the intensity of symptoms was found to equal 0.04 and be statistically insignificant $(\mathrm{P}>0.05)$; thus, both characteristics were found not to be significantly dependent on each other. However, this observation may warrant the conclusion that the shortening of the styloid process may be an efficient method of treatment even in patients with long-lasting, chronic pain disorders.

\section{SUMMARY}

Eagle's disease is a rare pathological entity. It is characterized by throat pain, exacerbating upon mastication, swallowing, or head movements, globus sensation, odynophagia, otalgia or migraine-like headaches. Eagle's syndrome should be taken into 
account in differential diagnostics of pain and neck disorders as carried out by dentists, otolaryngologists, neurologists, and anesthesiologists. Diagnosis is based on clinical examination and $\mathrm{CT}$ scans with 3D reconstruction facilitating the assessment of the styloid process' lengths and positions relative to cranial nerves within the parapharyngeal, carotid blood vessels, and lateral pharyngeal wall. As shown by this study, surgical treatment consisting in resection of the elongated styloid process if an efficient method of treatment that measurably reduces the pain experienced by patients.

\section{REFERENCES}

1. Al Weteid A.S., Miloro M.: Transoral endoscopic-assisted styloidectomy: How should Eagle syndrome be managed surgically? Int. J. Oral Maxillofac. Surg., 2015; 449: 1181-1187.

2. Bafaqeeh S.A.: Eagle Syndrome: classic and carotid artery types. J Otolaryngol, 2000; 29(2): 88.

3. Balcioglu H.A., Kilic C., Akyol M., Ozan H., Kokten G.: Length of the styloid process and anatomical implifications for Eagle's syndrome. Folia Morphol., 2009; 68(4): 265-270.

4. Beder E., Ozgursoy O.B., Ozgurosy S.K: Current Diagnosis and Transoral Surgical Treatment of Eagle's Syndrome J. Oral Maxillofac. Surg., 2005; 63(12): 1742-1745.

5. Bożyk A., Krawczyk J., Wiktor-Stoma A., Mieszkowski P., Borowicz J., RóżyłoKalinowska I.: The assessment of the size of the styloid process using CBCT. EJMT., 2014; 1(2): 29-37.

6. Ceylan A., Köybasioglu A., Çelenk F., Yilmaz O., Uslu S.: Surgical Treatment of elongated styloid process: experience of 61 cases. Skull Base., 2008; 18(5): 289-295.

7. Czajka M., Szuta M.: The long styloid process syndrome - a case report. Implantoprotetyka, 2007; 8(1-2): 26-27.

8. Eagle W.W.: Elongated styloid process: Report of two cases. Arch. Otolaryngol., 1937; 25(5): 584-587.

9. Diamond L.H., Cottrell D.A., Hunter M.J., Papageorge M.: Eagle's Syndrome: A report of 4 patients treated using a modified extraoral approach. J. Oral Maxillofac. Surg., 2001; 59(12): 1420-1426.

10. Fini G., Gasparini G., Filippini F., Becelli R., Marcotullio D.: The long styloid process syndrome or Eagle's Syndrome. Cranio-maxillofa Surg., 2000; 28(2): 123-127.

11. Fusco D.J., Asteraki S., Spetzler R.F.: Eagle's Syndrome: embryology, anatomy and clinical management. Acta Neurochir., 2012; 154(7): 1119-1126.

12. Kiralj A., Ilić M., Pejaković B., Markov B., Mijatov S., Mijatov I.: Eagle’s syndrome - a report of two cases., Vojnosanit Pregl., 2015; 72(5): 458-462.

13. Piagkou M., Anagnostopoulou S., Kouladouros K., Piagkos G.: Eagle's Syndrome: A review of the literature. Clinical anatomy, 2009; 22(5): 545-558.

14. Prasad K.C., Kamath M.P., Reddy K.J.M., Raju K., Agarwal S.: Elongated styloid process (Eagle's Syndrome): A clinical study. J. Oral Maxillofac Surg., 2002; 60(2): 171-175.

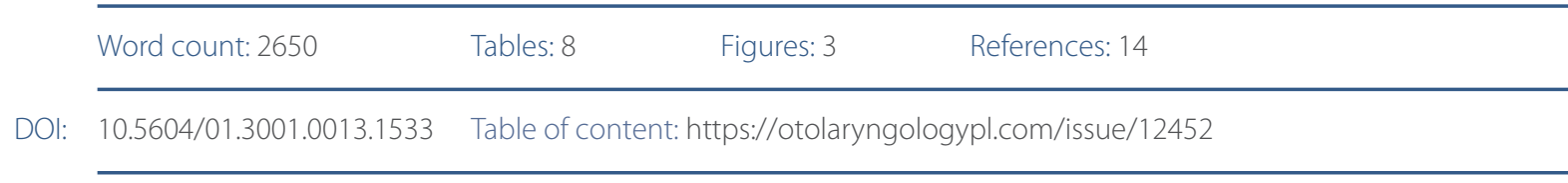 \\ Copyright: Copyright @ 2019 Polish Society of Otorhinolaryngologists Head and Neck Surgeons. Published by Index Copernicus Sp. z o.o. All rights reserved}

Competing interests: The authors declare that they have no competing interests.

T. The content of the journal „Polish Society of Otorhinolaryngologists Head and Neck Surgeons” is circulated on the basis of
the Open Access which means free and limitless access to scientific data.

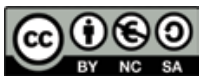

Corresponding author:

Cite this article as:
This material is available under the Creative Commons - Attribution 4.0 GB. The full terms of this license are available on: http://creativecommons.org/licenses/by-nc-sa/4.0/legalcode

Marcin Czajka; Klinika Chirurgii Czaszkowo-Szczękowo-Twarzowej, Onkologicznej i Rekonstrukcyjnej Instytut Stomatologii Uniwersytet Jagielloński Collegium Medicum, Os. Złotej Jesieni 1, 31-826 Kraków; E-mail: marcin.czajka@uj.edu.pl

Czajka M., Szuta M., Zapała J., Janecka I.: Assessment of the surgical management of Eagle's syndrome; Otolaryngol Pol 2019; 73 (5): 18-24 
